\title{
Phytochemical and pharmacological evaluations of Polygonum lapathifolium stem extract for anthelmintic and antiemetic activity
}

\author{
${ }^{*}$ Latifa Bulbul ${ }^{1}$, Somen Mojumder Sushanta ${ }^{1}$, Md. Jahir Uddin², Shahnaj Tanni ${ }^{3}$ \\ Department of Pharmacy, Noakhali Science and Technology University, Noakhali, Bangladesh
}

\begin{abstract}
The present study is an attempt to preliminary phytochemical investigation, anthelmintic and anti-emetic activity studies on methanolic extract of Polygonum lapathifolium stems. The phytochemical screening shows the presence of phytosterols, diterpens, amino acid \& protein, alkaloid and flavonoids, those are responsible for antiviral, antibacterial, antiallergic, antihypertensive, antiarrythmic, hepatoprotective, anti-inflammatory effects in mammals. In Anthelmintic activity test (using Pheretima posthuma model) five concentrations (20, 40, 60, 80 and $100 \mathrm{mg} / \mathrm{ml} \mathrm{in}$ distilled water) of extracts were used which involved the determination of time of paralysis (vermifuge) and time of death (vermicidal activity) of the worms, where the concentration of $60,80 \& 100 \mathrm{mg} / \mathrm{ml}$ showed a significant anthelmintic activity. Observations were comparable with the standard drug at concentration of $10 \mathrm{mg} / \mathrm{ml}$ of piperizine citrate. On the other hand, in anti-emetic test, emesis was induced by the oral administration of copper sulphate $50 \mathrm{mg} / \mathrm{kg}$ body weight to four days age of young chicks using chick emesis model. The antiemetic activity was determined by calculating the mean decrease in number of retching in contrast with those of control disorders. The extracts $(150 \mathrm{mg} / \mathrm{kg}$ orally) showed statistically significant antiemetic effect (90.45\% Inhibition) compared with reference drug metoclopramide (50mg/kg intraperitoneally) which showed $82.48 \%$ Inhibition. From these observations, it was concluded that stems extracts have potential anthelmintic and anti-emetic properties. The plant may further be explored for its various pharmacological activities.
\end{abstract}

Key Words: Polygonum lapathifolium, Pheretima posthuma, piperizine citrate, chick, metoclopramide, copper sulphate.

\section{INTRODUCTION}

The present study concentrates on the evaluation of phytochemical screening, anthelmintic and antiemetic activity of Polygonum lapathifolium stems extract. Helminthic infection is most prevalent disease in developing countries especially in Bangladesh. Mismanagement of anthelmintics, or development of resistance to various anthelmintic compounds increase its toxicity problems (Akhtar et al., 2000). Moreover synthetic drugs used in helminthiasis treatment have some potential side effects. Anthelmintics from natural sources could play a key role in the treatment of these parasite infections. Hence there is an increasing demand towards natural anthelmintics (Kumar et al., 2010). Antiemet-

\footnotetext{
*Corresponding Author:

Latifa Bulbul, Lecturer

Department of Pharmacy

Noakhali Science and Technology University

Sonapur-3814, Noakhali, Bangladesh

E-mail: prova_pharm32@yahoo.com

Contact No.: +8801741 676362
}

ics are typically used to treat motion sickness and the side effects of opioid analgesics, general anaesthetics, and chemotherapy directed against cancer (Fake et al., 2004; Sontakke and Thawani, 2003).

P. lapathifolium (s.1.), generally known as Knotweed belongs to the family Polygonaceae, is 2'-5' tall annual herb (Choudhary et al., 2011; Freckmann and Bowers, 2012). The plant grows in swampy areas, roadsides, floodplains andwaste places (Anjen et al., 2003). The round stems are hairless and somewhat swollen near the base of the leaves. The peduncles and pedicels often seem glandular. The alternate leaves are up to 2'-10' long and broader than those of the preceding. They are lanceolate, glabrous or slightly pubescent, and have smooth margins. At the base of each petiole of the leaves, there is a membraneous sheath (ocrea) that wraps around the stem (Britton and Brown, 1993). The upper stems terminate in spike-like racemes of flowers. The small flowers are densely crowded together along the 
length of the raceme. They are usually white or greenish white and less often light pink. Each flower is about $1 / 8^{\prime \prime}$ long, consisting of 5 sepals and no petals. Because the flowers usually don't open fully, the inner sepals are often difficult to observe. Each seed is dark brown or black, rather flat and oval in shape, and up to $2 \mathrm{~mm}$. across having a smooth shiny surface. The root system is shallow and fibrous (Peng, 1996). The genus primarily grows in northern temperate regions including Bangladesh, India, Britain, S. Africa (Choudhary et al., 2011; Freckmann and Bowers, 2012). The whole plant has antiseptic and astringent property. An infusion of root has been used in the treatment of stomach complaints and fevers. The plant is also applied externally on burns. Young leaves and seeds are used as raw or cooked form. The plant produces a soft white mass which is used for bathing and washing clothes (Freckmann and Bowers, 2012).

The family Polygonaceae consists of several important medicinal plants with wide range of biological activities and interesting phytochemical constituents. Various plants of Polygonaceae are used in the management of GI complication and helminthiasis treatment in traditional medicine (Hameed et al., 2008; Hussain et al., 2010). The selection of plant $P$. lapathifolium was based on its availability, therapeutic value and the degree of research work, which is not done mostly in earlier. Keeping in mind about the adverse effects of synthetic drugs available in the market, $P$. lapathifolium extracts were used for the screening of different pharmacological activities and active constituents present in the extract.

\section{MATERIALS AND METHODS}

\section{Collection and identification}

Plant sample of P. lapathifolium were collected from Noakhali Science and Technology University campus, Sonapur, Noakhali, in September 2012. The plant was identified by the expert of Bangladesh National Herbarium, Mirpur, Dhaka, Bangladesh (Identification number-37924).

\section{Preparation of the plant materials}

The stems of the plant were collected and washed thoroughly with water several times. During collection any type of adulteration was strictly prohibited. The steams of the plant were collected in fresh condition. It was sun-dried and then dried in an oven at reduced temperature (not more than $50^{\circ} \mathrm{C}$ ) to make it suitable for grinding. The coarse powder was then stored in air-tight container with marking for identification and kept in cool, dark and dry place for future use.

\section{Extraction of the plant material}

The dried and ground plant powder of P. lapathifolium stems $(350 \mathrm{gm})$ were soaked in 1.3liter methanol. Plant powders were kept in separate desiccators at room temperature with occasional stirring and shaking for 15 days. The extract was then filtered through filter-cloth. The filtrate was kept to dry in fresh and clean air to afford a greenish mass of biological investigation.

\section{Worm collection and authentication}

Earthworms, Pheretima posthuma (Annelida), were collected from moist soil at Noakhali Science and Technology University, Noakhali Dhaka and washed with normal saline to remove soil and fecal matter. Earthworms were identified by Fisheries and Marin Science Dept, Noakhali Science and Technology University. The earthworms of $4-6 \mathrm{~cm}$ in length and $0.2-0.3 \mathrm{~cm}$ in width were used for the experimental protocol.

\section{Animals}

Young male chicks, 2- 4 days of age, weighing from 32-52 gm were obtained from a poultry local store. After $24 \mathrm{hrs}$ fasting, the antiemetic activity was evaluated. All chicks were kept under laboratory conditions at room temperature with $12 \mathrm{~h}$ light and dark cycles. All animal experiments were carried out in accordance with the acts of the Animal Ethical Committee of NSTU Research Cell, Noakhali Science and Technology University.

\section{Chemicals}

Piperazine Citrate was purchased from GlaxoSmithKline (BD) Limited. Copper sulfate was purchased from Scharlau Chem-ie S.A. Barcelona, Spain. Metoclopramide hydrochloride was purchased from. Dimethyl sulfoxide (DMSO), Polyoxyethylene sorbitan monooleate (Tween 80) and methanol were purchased from Merck, Darm-stadt, Germany. Acetic anhydride, Sulphuric acid, lead acetate, Nitric acid, Copper acetate were also purchased from Merck, Darm-stadt, Germany. All 
other reagents were procured from Sigma Chemicals limited.

\section{Phytochemical Screening}

Preliminary phytochemical study was screened for presence of alkaloid, phenols, phytosterols, Saponins, proteins and aminoacids, flavonoids and diterpenes where phenols and saponins are absent in extracts. These were identified by characteristic colour changes using standard procedures (Hosahally et al., 2012; Nasrin, 2013; Trease and Evans, 1989).

\section{Detection of alkaloids}

Hager's Test: Extracts were dissolved individually in dilute Hydrochloric acid and the solutions were filtered. Filtrates were treated with Hager's reagent (saturated picric acid solution). Presence of alkaloids was confirmed by the formation of yellow colored precipitate.

\section{Detection of phytosterols}

Libermann Burchard's test: Extracts were treated with chloroform and filtered. The filtrates were treated with few drops of acetic anhydride, boiled and cooled. Conc. Sulphuric acid was added. Formation of brown ring at the junction indicates the presence of phytosterols.

\section{Detection of flavonoids}

Lead acetate test: Extracts were treated with 4-5 drops of lead acetate solution. Formation of yellow color precipitate indicates the presence of flavonoids.

\section{Detection of proteins and aminoacids}

Xanthoproteic test: The extracts were treated with 45 drops of conc. Nitric acid. Formation of yellow color indicates the presence of proteins.

\section{Detection of diterpenes}

Copper acetate test: Extracts were dissolved in water and treated with 3-4 drops of copper acetate solution. Formation of emerald green color indicates the presence of diterpenes.

\section{Anthelminic activity}

The anthelmintic assay was carried as per the method of Ajaiyeoba et al. (2001) with minor modifications. In this experiment, Pheretima posthu$m a$ were used because of its anatomical and physiological similarity with intestinal roundworm parasites of human beings and they are belonging to same group of Annelida. The earthworms were divided into different groups with equal size and each group containing six worms. $60 \mathrm{ml}$ formulations containing five different concentrations of methanolic extract of P. lapathifolium (20, 40, 60, 80 and $100 \mathrm{mg} / \mathrm{ml}$ in distilled water) were prepared. Piperazine citrate $(10 \mathrm{mg} / \mathrm{ml})$ was used as reference standard while saline water served as a control. All the test solution and standard solution were prepared freshly before starting experiments. The time for paralysis was noted when no movement of any sort could be observed except when the worms were shaken vigorously. The times of death of the worms were recorded after ascertaining that worms neither moved when shaken vigorously or when dipped in warm water $\left(50^{\circ} \mathrm{C}\right)$.

\section{Antiemetic activity}

The 4 days old chicks were divided into four groups of five chicks each and each chick was kept in a large beaker at $25^{\circ} \mathrm{C}$ for 10 minutes. The antiemetic effect was determined by calculating the mean decrease in number of retching following the protocols of Akita et al. (1998). The extracts of $P$. lapathifolium stems were dissolved in $0.9 \%$ saline containing 5\% DMSO and 1\% Tween 80 and administered at a dose of $150 \mathrm{mg} / \mathrm{kg}$ orally and volume of $10 \mathrm{ml} / \mathrm{kg}$ to the test animal on the basis of their body weights. Control group received only saline $0.9 \%$. After 10 minutes copper sulphate was administered orally at $50 \mathrm{mg} / \mathrm{kg}$, then the number of retching was observed during next ten minutes. Metoclopramide was used as a standard drug (50 $\mathrm{mg}$ per $\mathrm{kg}$ body weight intraperitoneally. The antiemetic effect was assessed as the decrease in number of retches in the treated group in contrast to the control. The inhibition (\%) was calculated as follows:

Inhibition (\%) $=\frac{A-B}{A} \times 100$

where $\mathrm{A}$ is the control frequency of retching and $\mathrm{B}$ is the frequency of retching of the treated group.

\section{Statistical analysis}

In case of anthelmintic activity test, the experimental data were calculated as were calculated as Mean \pm SEM, evaluated by unpaired one way ANOVA. Test values of $\mathrm{P}<0.01$ were considered statistically significant. All numerical data are expressed as the 
Table 1: Anthelmintic activity of methanolic extracts of $P$. lapathifolium stems.

\begin{tabular}{lcccc}
\hline \multirow{2}{*}{ Groups } & \multicolumn{2}{c}{ Concentration $\mathbf{( m g / m l )}$} & $\begin{array}{c}\text { Time taken for paralysis } \\
\text { in min. (Mean } \pm \text { S.E.M) }\end{array}$ & $\begin{array}{c}\text { Time taken for Death } \\
\text { in min. (Mean } \pm \text { S.E.M) }\end{array}$ \\
\cline { 2 - 4 } Control & Piperazine citrate & Methanolic extract & - & - \\
Reference standard & - & - & $9.33 \pm 0.33$ & $36.00 \pm 1.15$ \\
Group 1 & 10 & - & $19.33 \pm 1.45$ & $38.00 \pm 1.73$ \\
Group 2 & - & 20 & $17.33 \pm 2.18$ & $29.66 \pm 0.33$ \\
Group 3 & - & 40 & $9.00 \pm 1.45$ & $23.66 \pm 2.66$ \\
Group 4 & - & 60 & $5.66 \pm 1.15$ & $20.33 \pm 0.66$ \\
Group 5 & - & 80 & $3.67 \pm 1.02$ & $15.04 \pm 1.64$ \\
\hline
\end{tabular}

mean \pm standard error of mean (SEM). In case of antiemetic test, statistical analysis was carried out using student's t-test and differences between means were considered to be significant when $\mathrm{p}<0.05$.

\section{RESULTS AND DISCUSSION}

Phytochemical screening

Preliminary phytochemical screening of the extract revealed the presence of flavanoid, protein \& aminoacids, alkaloid, diterpenes and phytosterols compounds.

\section{Anthelmintic activity}

Crude methanolic extracts of stem of inhibited earthworms in a dose-dependent manner. In case of stem extract, the paralysis time at different concentrations, including $20 \mathrm{mg} / \mathrm{ml}, 40 \mathrm{mg} / \mathrm{ml}, 60 \mathrm{mg} / \mathrm{ml}, 80$ $\mathrm{mg} / \mathrm{ml}$ and was 19.33,17.33, 9.00, 5.66, 3.67 minutes respectively, whereas death time was 36, 38, 29.66, 23.66, 20.33 and 15.04 minutes respectively. The paralysis and dead time for standard piperazine citrate at a concentration of $10 \mathrm{mg} / \mathrm{ml}$ were 9.33 and 36.15 minutes, respectively (Table 1 and Figure 1).

From the phytochemical detectection in the methanolic extract acting as a major role to possess anthelmintic properties. From Phytochemical investigation, the presence of flavon content which may be sole responsible for activity (Paria et al., 2012) From the table 1, mainly methanolic stems extract containing 60,80 and $100 \mathrm{mg} / \mathrm{ml}$ showed a significant anthelmintic activity comparable with the standard drug at concentration of $10 \mathrm{mg} / \mathrm{ml}$ of piperizine citrate produces dose-dependent paralysis ranging from loss of motility to loss of response to external stimuli, which gradually progressed to death. Further attention has to be carried out for isolation and characterization of the active components to establish an effective drug resource scientifically.

\section{Antiemetic activity}

Result of the antiemetic activity of methanolic extracts of $P$. lapathifolium stem is given in table 2 . After administration of a dose of $50 \mathrm{mg} / \mathrm{kg}$ BW Metoclopramide and the extracts of stems, the numbers of retches were reduced. The group of chicks treated with Metoclopramide was found to have 11 retches as compared to the 62 retches of control group, thus Metoclopramide reduced the retches by $82.48 \%$. The chicks treated with steams extract was found to have 6 retches and inhibited the retches up to $90.45 \%$. Therefore, the extract of Steams inhibited emesis to an extant greater than Metoclopramide at $50 \mathrm{mg} / \mathrm{kg}$ (Figure 2). On the basis of these results it may be concluded that extracts of stems have anti-emetic potential and are comparable with that of Metoclopramide (the reference drug). Although the results are significant but the mode of action is not known.

However, as the oral copper sulphate induces emesis by peripheral action (Hosseinzadeh et al., 2008), and the extracts were able to effectively prevent its effect, it could be implied that these extracts have a peri-

Table 2: Antiemetic activities of methanolic extracts of $P$. lapathifolium Stems.

\begin{tabular}{lcc}
\hline Drug / dose & $\begin{array}{c}\text { No. of retches } \\
\text { (Mean } \pm \text { S.E.M) }\end{array}$ & \% Inhibition \\
\hline $\begin{array}{l}\text { Control }(10 \mathrm{ml} / \mathrm{kg}) \\
\begin{array}{l}\text { Metoclopramide } \\
(50 \mathrm{mg} / \mathrm{kg})\end{array}\end{array}$ & $62.00 \pm 1.58$ & - \\
$\begin{array}{l}\text { P. lapathifolium Stems } \\
(150 \mathrm{mg} / \mathrm{kg})\end{array}$ & $11 \pm 1.89$ & $82.48 \%$ \\
\hline
\end{tabular}




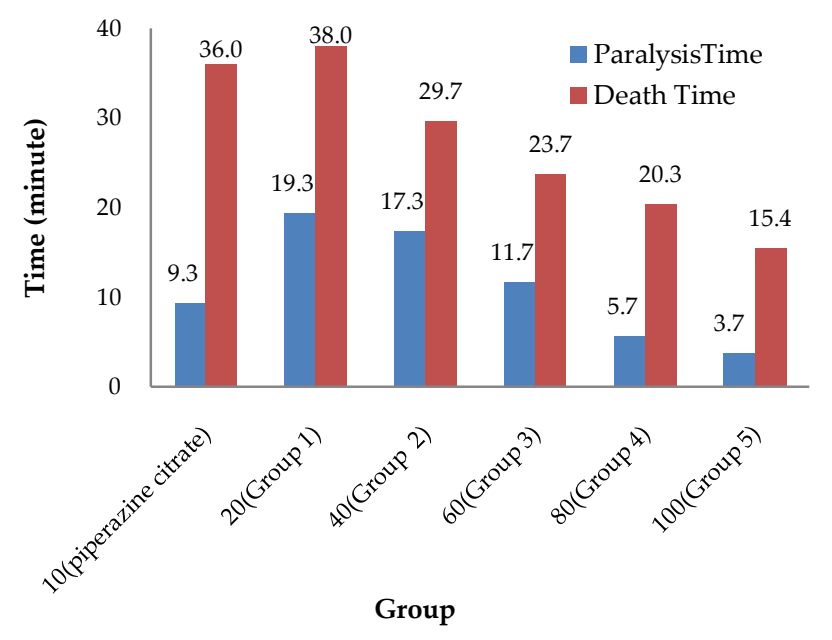

Figure 1: Paralysis Time and Death Time of P. posthuma for standard and stems extract.

pheral anti-emetic action. This study also justifies the traditional use of P. lapathifolium in G.I.T complaints. From chemical point of view, stem of P. lapathifolium contain alkaloids and showed highest activity as compared to standard. Therefore, it may be said that alkaloidal contents may play some role in anti-emetic effect (Hasan et al., 2012).

Chemotherapeutic agents or their metabolites can directly activate the medullary chemoreceptor trigger zone or vomiting center or act peripherally by causing cell damage in the gastro-intestinal tract and releasing serotonin from enterochromaffin cells of the small intestinal mucosa. The released serotonin activates 5-HT receptors on vagal and splanchnic afferent fibers, which then carry sensory signals to the medulla, leading to the emetic response (Hosseinzadeh et al., 2008; Sontakke and Thawani, 2003). Metoclopramide, which has already been known to elicit antiemetic activity through acceleration of gastrointestinal tract movement (Ahmed et al., 2011), was found to be less effective than stem extracts. The ability of extracts to significantly attenuate the effect of copper sulphateinduced emesis in chicks may in part be due to its effect on the visceral afferent sympathetic fibre in the GIT and possibly through agonistic effect at the inhibitory receptor sites such as dopamine and GABA in central nervous system (Zia-Ul-Haq et al., 2012). The observed antiemetic activity of $P$. lapathifolium stems extract may be attributed to its alkaloid and terpenes constituents. Until now, no other research papers are found to the antiemetic activity of

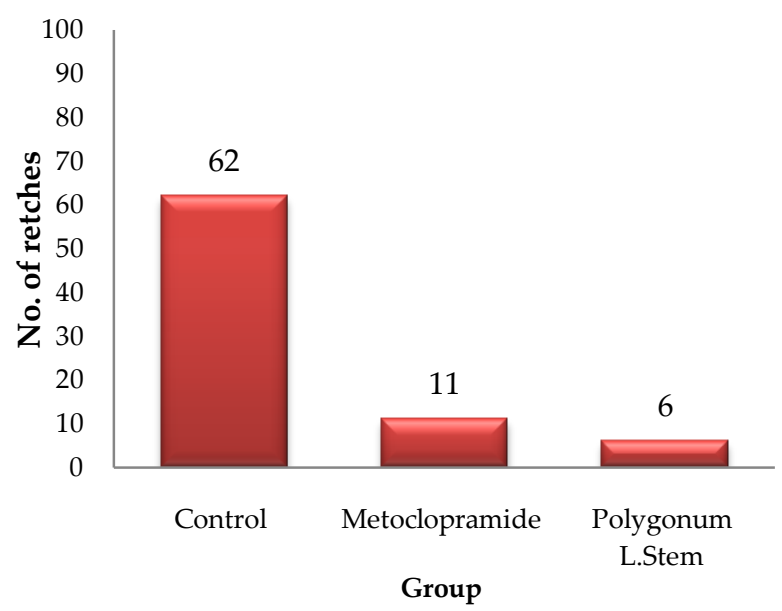

Figure 2: Number of retches for control, standard and methanolic extracts of $P$. lapathifolium Stems.

P. lapathifolium stems extract and thus provides scientific basis for its use in folk medicine for the management of GI complication. Further studies are required to determine the exact mode of action and the active compounds responsible for this effect.

\section{CONCLUSION}

The results of this study suggest that the methanolic extracts of stem of $P$. lapathifolium have shown active in vitro anthelmintic effect against adult stage of Pheretima posthuma. On the other hand, the stem extracts have protective effects against copper sulfate induced-retching in young chickens, possibly by peripheral and central mechanisms. Further studies are required to recognize active constituents and the molecular mechanism of anthelmintic and antiemetic activities.

\section{ACKNOWLEDGEMENT}

The authors are thankful to all faculty members and the technical and non technical staffs of the Department of Pharmacy, Noakhali Science and Technology University, Bangladesh for their kind co-operation. 


\section{REFERENCES}

Ahmed, S., Sultana, M., Hasan, M. M.U. and Azhar, I. (2011). Analgesic and Antiemetic activity of Cleome viscosa L. (Medicinal Plants: Conservation and Sustainable use). Pak. J. Bot., Volume 43, Pages 119-122.[Link]

Ajaiyeoba, E.O., Onocha, P.A., and Larenwaju, O.T.O. (2001). In vitro anthelmintic properties of Buchholzia coriaceae and Gynandropsis gynandra extract. Pharm Biol., Volume 39, Pages 217-220. [DOI]

Akhtar, M.S., Iqbal, Z., Khanb, M.N., Lateef, M. (2000). Anthelmintic activity of medicinal plants with particular reference to their use in animals in the Indo Pakistan subcontinent. Small Ruminant Research, Elsevier, Volume 38, Issue 99, Pages 107. [DOI]

Akita, Y., Yang, Y., Kawai, T., Kinoshita, K., Koyama, K., Takahashi, K. (1998). New assay Method for surveying antiemetic compounds from natural sources. Nat. Prod. Sci., Volume 4, Pages 72- 77.

Anjen, L., Alisa, E.G., Suk-pyo, H., McNeill, J., Hideaki, O., Park,C. liao, M.(2003). Flora of China, Volume 5, Pages: 278-315.

Britton, N. L. and Brown, A. (1993). An Illustrated Flora of The Northern United States, Canada And The British Possessions Vol2. Charles Scribner's Sons. [DOI]

Choudhary, R. K., Oh, S., and Lee, J. (2011). An ethnomedicinal inventory of knotweeds of Indian Himalaya. Journal of Medicinal Plants Research, Volume 5, Issue 10, Pages 2095-2103.

Fake, A.Z., Scalley, R.D., Bailey, A.G. (2004), Practical Selection of Antiemetics, Am Fam Physician, Volume 69, Issues 5, Pages 1169-1174.

Freckmann, W.R. and Bowers, W.F. (2012) Robert W. Freckmann Herbarium (Polygonum lapathifolium L). University of Wisconsin - Stevens Point. [Link]

Hameed, I., Hastagir, G., and Hussain, F. (2008). Nutritional and elemental analyses of some selected medicinal plants of the family polygonaceae. Pak. J. Bot., Volume 40, Issues 6, Pages 2493-2502.

Hasan, M.M.U., Azhar, I., Muzammil, S., Ahmed, S. and Ahmed, S.W. (2012). Anti-emetic activity of some leguminous plants. Pak. J. Bot., Volume 44, Issue 1, Pages 389391. [Link]

Hosahally, V.R., Seru, G., Sutar, S.P., Joshi, G.V., Sutar, P.K., Karigar, A.A.,(2012). Phytochemical and pharmacological evaluation of Tragia cannabina for anti-inflammatory activity. International Current Pharmaceutical Journal, Volume 1, Issue 8, Pages 213-216. [DOI]

Hosseinzadeh, H., Mirshojaeian, M., Razavi, B.M. (2008). Antiemetic Effect of Pistacia vera L. (Pistachio) Leaves and Nuts Aqueous Extracts in Young Chicken. Pharmacologyonline, Volume 2, Pages 568-571. [Link]
Hussain, F., Hameed, I., Dastagir, G., Shams-un-Nisa, Khan, I. and Ahmad, B. (2010). Cytotoxicity and phytotoxicity of some selected medicinal plants of the family Polygonaceae, African Journal of Biotechnology, Volume 9, Issues 5, Pages 770-774.

Kumar, B.S.A., Lakshman, K., Jayaveera, K.N., Nandeesh, R., Manoj, B. and Ranganayakulu, D. (2010). Comparative in vitro anthelmintic activity of three plants from the amaranthaceae family. Arch. Biol. Sci., Belgrade, Volume 62, Issues 1, Pages 185-189. [DOI]

Nasrin, F. (2013). Antioxidant and cytotoxic activities of Ageratum conyzoides stems, International Current Pharmaceutical Journal, January, Volume 2, Issues 2, Pages 33-37. [DOI]

Paria, S., Maity, S. and Mookerjee, M. (2012). Phytochemial Investigation and Evaluation of Anthelmintic activities of $V$. Negundo Leaf Extract. International Journal of Research in Pharmaceutical and Biomedical Sciences, Volume 3, Issues 3, Pages 1143-1146. [Link]

Peng, I.C. (1996). Flora of Taiwan, $2^{\text {nd }}$ ed., Volume 2, Pages 304. [Link]

Sontakke, V., Thawani, M.S. Naik.( 2003). Ginger as an antiemetic in nausea and vomiting induced by chemotherapy: a randomized, cross-over, double blind study. Indian Journal of Pharmacology, Volume 35, Pages 32-36.

Trease, G.E., Evans WC. (1989). Text book of Pharmacognosy. $13^{\text {th }}$ (eds). Alden Press; Oxford; Pages 512-513.

Zia-Ul-Haq, M., Shahid, S.A., Muhammed, S., Qayum, M., Khan, I. and Ahmad, S. (2012). Antimalarial, antiemetic and antidiabetic potential of Grewia aslatica L. leaves. Journal of Medicinal Plants Research, Volume 6, Issues 16, Pages 3213-3216. [DOI] 